\title{
Predictors of Morbidity and Mortality After Surgery for Intestinal Perforation
}

\author{
Rumi Shin, Sang Mok Lee, Beonghoon Sohn, Dong Woon Lee ${ }^{1}$, Inho Song ${ }^{1}$, Young Jun Chai, \\ Hae Won Lee, Hye Seong Ahn, In Mok Jung, Jung Kee Chung, Seung Chul Heo \\ Department of Surgery, Seoul Metropolitan Government-Seoul National University Boramae Medical Center, Seoul; ${ }^{1}$ Department of Surgery, \\ Seoul National University College of Medicine, Seoul, Korea
}

Purpose: An intestinal perforation is a rare condition, but has a high mortality rate, even after immediate surgical intervention. The clinical predictors of postoperative morbidity and mortality are still not well established, so this study attempted to identify risk factors for postoperative morbidity and mortality after surgery for an intestinal perforation.

Methods: We retrospectively analyzed the cases of 117 patients who underwent surgery for an intestinal perforation at a single institution in Korea from November 2008 to June 2014. Factors related with postoperative mortality at 1 month and other postoperative complications were investigated.

Results: The mean age of enrolled patients was $66.0 \pm 15.8$ years and $66 \%$ of the patients were male. Fifteen patients $(13 \%)$ died within 1 month after surgical treatment. Univariate analysis indicated that patient-related factors associated with mortality were low systolic and diastolic blood pressure, low serum albumin, low serum protein, low total cholesterol, and high blood urea nitrogen; the surgery-related factor associated with mortality was feculent ascites. Multivariate analysis using a logistic regression indicated that low systolic blood pressure and feculent ascites independently increased the risk for mortality; postoperative complications were more likely in both females and those with low estimated glomerular filtration rates and elevated serum C-reactive protein levels.

Conclusion: Various factors were associated with postoperative clinical outcomes of patients with an intestinal perforation. Morbidity and mortality following an intestinal perforation were greater in patients with unstable initial vital signs, poor nutritional status, and feculent ascites.

Keywords: Intestinal perforations; Postoperative mortality; Postoperative complications; Ascites

\section{INTRODUCTION}

An intestinal perforation is a major life-threatening condition with high morbidity and mortality that requires emergency surgery. Despite improvements in surgical and medical treatments, the overall mortality rate is $30 \%$ and the mortality rate of cases

Received: September 12, 2016 - Accepted: October 23, 2016

Correspondence to: Seung Chul Heo, M.D.

Department of Surgery, Seoul Metropolitan Government-Seoul National University Boramae Medical Center, 20 Boramae-ro 5-gil, Dongjak-gu, Seoul 07061, Korea

Tel: +82-2-870-2273, Fax: +82-2-870-3866, E-mail: heosc3@brmh.org

(C) 2016 The Korean Society of Coloproctology

This is an open-access article distributed under the terms of the Creative Commons Attribution NonCommercial License (http://creativecommons.org/licenses/by-nc/4.0) which permits unrestricted noncommercial use, distribution, and reproduction in any medium, provided the original work is properly cited. that also have diffuse peritonitis is up to $70 \%$ [1-4]. The rate of postoperative complications, such as complicated fluid collection, leakage, surgical site infection, and other systemic infections, is higher than for patients receiving elective abdominal surgeries. Various factors can cause intestinal perforation, including ischemic colitis, intestinal obstruction, stercoral perforation, infection, cancer, diverticulitis, trauma, and colonoscopy $[2,5,6]$. Perforations due to cancer and infection have high mortality rates $[7,8]$, but iatrogenic perforation during colonoscopy has a low mortality rate [9]. Several studies have identified prognostic factors associated with morbidity and mortality for patients with an intestinal perforation $[1,10]$, and several scoring systems are available [11, 12]. However, these risk factors and scoring systems have only been validated in small study populations and are not clinically useful in emergency situations. Thus, the aim of the present study was to identify simple and intuitive patient-related and surgery- 
related prognostic factors associated with postoperative morbidity and mortality for patients with an intestinal perforation.

\section{METHODS}

This retrospective study was performed at the Seoul Metropolitan Government-Seoul National University Boramae Medical Center. From November 2008 to June 2014, 123 consecutive patients underwent an exploratory laparotomy due to a suspected intestinal perforation. Of those, the 117 patients who were over 18 years of age and who had confirmed intestinal perforations were included in this study. Clinical data, laboratory data, and operative findings were collected by reviewing their medical records. Postoperative complications were defined as complicated fluid collection, anastomosis leakage, surgical site infection, ileus, pneumonia, enterocutaneous fistula, cardiovascular events, multiorgan failure, and septic shock. The study protocol was approved by the Institutional Review Board of Seoul Metropolitan Government-Seoul National University Boramae Medical Center (approval number: 26-2016115).

The chi-square test or Fisher exact test was used to compare survivors and nonsurvivors. A multivariable logistic regression model was used to the calculate odds ratios (ORs) and the 95\% confidence intervals (95\% CIs) and to identify factors independently associated with postoperative mortality. The multivariable model was constructed using a forward Wald test, with adjustment for age, sex, body mass index (BMI), surgical procedure, feculent ascites, fever, time from symptom onset to surgery, time from admission to surgery, length of surgery, initial systolic and diastolic blood pressure, heart rate, and comorbidities. The 1-month postoperative survival curve was estimated using the Kaplan-Meier method, and the log-rank test was used to determine the significance of differences according to the presence of feculent ascites. For all analyses, a two-tailed P-value of 0.05 or less was considered significant. All statistical analyses were performed using IBM SPSS Statistics ver. 19.0 (IBM Co., Armonk, NY, USA).

Table 1. Etiology of the intestinal perforation in the study population $(\mathrm{n}=117)$

\begin{tabular}{lc}
\hline Etiology & No. (\%) \\
\hline Ischemic colitis & $8(6.8)$ \\
Obstruction & $12(10.3)$ \\
Stercoral perforation & $8(6.8)$ \\
Infection & $2(1.7)$ \\
Endoscopic complication & $18(15.4)$ \\
Cancer perforation & $9(7.7)$ \\
Complicated diverticulitis & $14(12.0)$ \\
Traumatic & $12(10.3)$ \\
Others & $34(29.1)$ \\
\hline
\end{tabular}

\section{RESULTS}

The mean age of enrolled patients was $66.0 \pm 15.8$ years, and $66 \%$ were male. The most common causes of intestinal perforation were complications from endoscopy $(15.4 \%)$ and complicated diverticulitis (12.0\%) (Table 1). Resection and anastomosis (R\&A) was the most common operation (Fig. 1). The mean time from symptom onset to surgery was $2.1 \pm 1.7$ days, and that from admission to surgery was $35.9 \pm 92.0$ hours.

Fifteen patients (12.8\%) died within 1 month after the index surgery. Table 2 shows the factors associated with postoperative mortality. Analysis of patient-related factors indicated that deceased patients had lower initial systolic blood pressure (121.6 \pm $26.2 \mathrm{mmHg}$ vs. $100.8 \pm 28.1 \mathrm{mmHg}, \mathrm{P}=0.005)$ and diastolic blood pressure $(73.7 \pm 15.2 \mathrm{mmHg}$ vs. $53.5 \pm 17.1 \mathrm{mmHg}, \mathrm{P}<$ $0.001)$, and lower levels of serum albumin $(3.3 \pm 0.6 \mathrm{~g} / \mathrm{dL}$ vs. $3.0 \pm$ $0.5 \mathrm{~g} / \mathrm{dL}, \mathrm{P}=0.048)$, serum protein $(5.6 \pm 1.2 \mathrm{~g} / \mathrm{dL}$ vs. $4.9 \pm 1.5 \mathrm{~g} /$ $\mathrm{dL}, \mathrm{P}=0.032)$, and total cholesterol $(124.6 \pm 4.97 \mathrm{mg} / \mathrm{dL}$ vs. 97.0 $\pm 50.0 \mathrm{mg} / \mathrm{dL}, \mathrm{P}=0.047$ ), but a higher level of blood urea nitrogen $(25.3 \pm 20.6 \mathrm{mg} / \mathrm{dL}$ vs. $40.1 \pm 33.4 \mathrm{mg} / \mathrm{dL}, \mathrm{P}=0.020)$. Analysis of surgery-related factors indicated that feculent ascites $(19.6 \%$ vs. $53.3 \%, \mathrm{P}=0.008$ ) was significantly more common in deceased patients. The multivariate analysis using a logistic regression model indicated that feculent ascites (OR, 4.948; $\mathrm{P}=0.007 ; 95 \%$ CI, 1.564-15.654) and systolic blood pressure less than 100 $\mathrm{mmHg}(\mathrm{OR}, 4.399 ; \mathrm{P}=0.013$; 95\% CI, 1.367-14.156) were independent and significant risk factors for postoperative mortality (Table 3). In agreement, the Kaplan-Meier survival analysis showed that the 1-month mortality was greater for patients with feculent ascites than those with non-feculent ascites $(29.6 \%$ vs. 8.2\%, Log-rank test: $\mathrm{P}=0.003$ ) (Fig. 2).

Postoperative complications occurred in 70 patients $(60 \%)$ (Fig. $3)$. The most common complications were surgical site infection $(\mathrm{n}=21)$, pneumonia $(\mathrm{n}=18)$, and complicated fluid collection ( $\mathrm{n}$ $=18$ ). The highest mortality rates occurred in patients with multi-

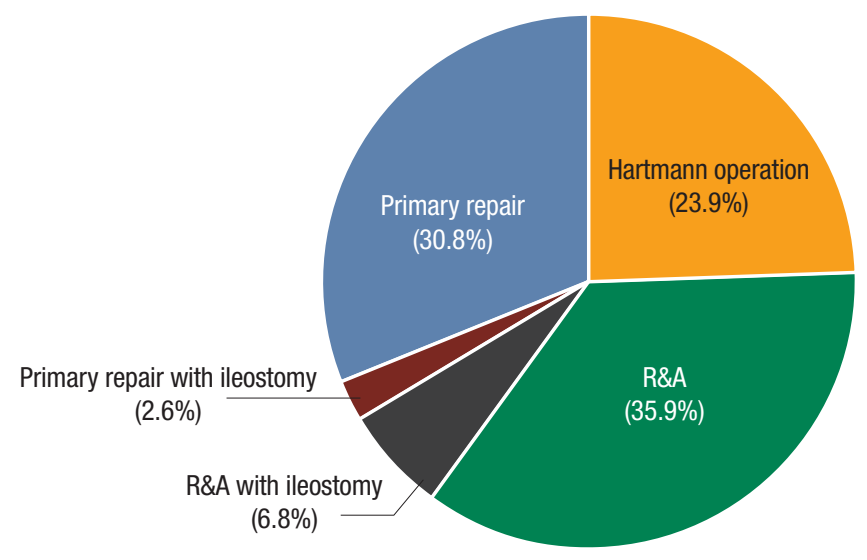

Fig. 1. Surgical methods used to treat patients with intestinal perforations $(n=117)$. $R \& A$, resection and anastomosis. 
Table 2. Univariate analysis of patient-related and operation-related factors associated with mortality within one month after surgery for an intestinal perforation

\begin{tabular}{|c|c|c|c|}
\hline Factor & Survivors $(n=102)$ & Nonsurvivors $(n=15)$ & P-value \\
\hline Age (yr) & $64.9 \pm 16.5$ & $71.9 \pm 9.4$ & 0.110 \\
\hline Male sex (\%) & 69.0 & 46.7 & \\
\hline Body mass index (kg/m) & $21.7 \pm 3.8$ & $21.7 \pm 6.0$ & 0.980 \\
\hline \multicolumn{4}{|l|}{ Past medical history } \\
\hline Cardiovascular disease & $7(7.0)$ & $1(6.7)$ & 1.000 \\
\hline Cerebrovascular accident & $3(3.0)$ & $1(6.7)$ & 0.433 \\
\hline Diabetes mellitus & $12(12.0)$ & $3(20.0)$ & 0.412 \\
\hline Hypertension & $27(27.0)$ & $7(46.7)$ & 0.137 \\
\hline Systolic blood pressure (mmHg) & $121.6 \pm 26.2$ & $100.8 \pm 28.1$ & $0.005^{\star}$ \\
\hline Diastolic blood pressure (mmHg) & $73.7 \pm 15.2$ & $53.5 \pm 17.1$ & $<0.001^{*}$ \\
\hline Heart rate (bpm) & $96 \pm 24$ & $104 \pm 29$ & 0.206 \\
\hline Body temperature $\left({ }^{\circ} \mathrm{C}\right)$ & $36.7 \pm 0.8$ & $36.2 \pm 1.4$ & 0.172 \\
\hline White blood cells $\left(/ \mathrm{mm}^{3}\right)$ & $9,510 \pm 5,703$ & $9,289 \pm 6,886$ & 0.892 \\
\hline C-reactive protein (mg/L) & $10.2 \pm 11.0$ & $11.4 \pm 9.5$ & 0.702 \\
\hline Serum albumin (g/dL) & $3.3 \pm 0.6$ & $3.0 \pm 0.5$ & $0.048^{*}$ \\
\hline Serum protein (g/dL) & $5.6 \pm 1.2$ & $4.9 \pm 1.5$ & $0.032^{*}$ \\
\hline Total cholesterol (mg/L) & $124.6 \pm 49.7$ & $97.0 \pm 50.0$ & $0.047^{\star}$ \\
\hline Blood urea nitrogen (mg/dL) & $25.3 \pm 20.6$ & $40.1 \pm 33.4$ & $0.020^{*}$ \\
\hline Creatinine (mg/dL) & $1.5 \pm 1.5$ & $2.2 \pm 2.3$ & 0.258 \\
\hline $\mathrm{eGFR}\left(\mathrm{mL} / \mathrm{min} / 1.73 \mathrm{~m}^{2}\right)$ & $73.2 \pm 30.8$ & $57.5 \pm 43.7$ & 0.088 \\
\hline PT INR & $1.23 \pm 0.35$ & $1.58 \pm 0.91$ & 0.201 \\
\hline aPTT (sec) & $31.1 \pm 13.7$ & $31.1 \pm 14.7$ & 0.990 \\
\hline Operation methods & & & 0.476 \\
\hline Hartmann operation & $24(23.5)$ & $4(26.7)$ & \\
\hline$R \& A$ & $37(36.3)$ & $5(33.3)$ & \\
\hline R\&A with ileostomy & $6(5.9)$ & $2(13.3)$ & \\
\hline Primary repair with ileostomy & $2(2.0)$ & $1(6.7)$ & \\
\hline Primary repair & $33(32.4)$ & $3(20.0)$ & \\
\hline Feculent ascites & 19 (19.6) & $8(53.3)$ & $0.008^{*}$ \\
\hline Site of perforation & & & 0.347 \\
\hline Colon & $56(54.9)$ & $10(66.7)$ & \\
\hline Rectum & $8(7.8)$ & $0(0)$ & \\
\hline Small bowel & $26(25.5)$ & $5(33.3)$ & \\
\hline Duodenum & $10(9.8)$ & $0(0)$ & \\
\hline Multiple sites & $2(2.1)$ & $0(0)$ & \\
\hline Time from symptom onset to surgery (day) & $2.8 \pm 5.6$ & $2.1 \pm 3.5$ & 0.625 \\
\hline Time from admission to surgery (hr) & $33.2 \pm 90.3$ & $41.1 \pm 93.5$ & 0.752 \\
\hline Length of surgery (min) & $175.2 \pm 80.5$ & $148.3 \pm 56.4$ & 0.215 \\
\hline
\end{tabular}

Values are presented as mean \pm standard deviation or number (\%) unless otherwise indicated.

eGFR, estimated glomerular filtration rate; PT INR, prothrombin time international normalized ratio; aPTT, activated partial thromboplastin time; R\&A, resection and anastomosis.

${ }^{*} \mathrm{P}<0.05$, statistically significant. 
Table 3. Multivariable analysis of factors associated with mortality within one month after surgery for an intestinal perforation

\begin{tabular}{lccc}
\hline Factor & Adjusted OR & $95 \% \mathrm{Cl}$ & P-value \\
\hline Feculent ascites & 4.948 & $1.564-15.654$ & $0.007^{\star}$ \\
$\mathrm{sBP}<100 \mathrm{mmHg}$ & 4.399 & $1.367-14.156$ & $0.011^{*}$ \\
\hline
\end{tabular}

$\mathrm{OR}$, odds ratio; $\mathrm{Cl}$, confidence interval; $\mathrm{SBP}$, systolic blood pressure.

${ }^{*} \mathrm{P}<0.05$, statistically significant.

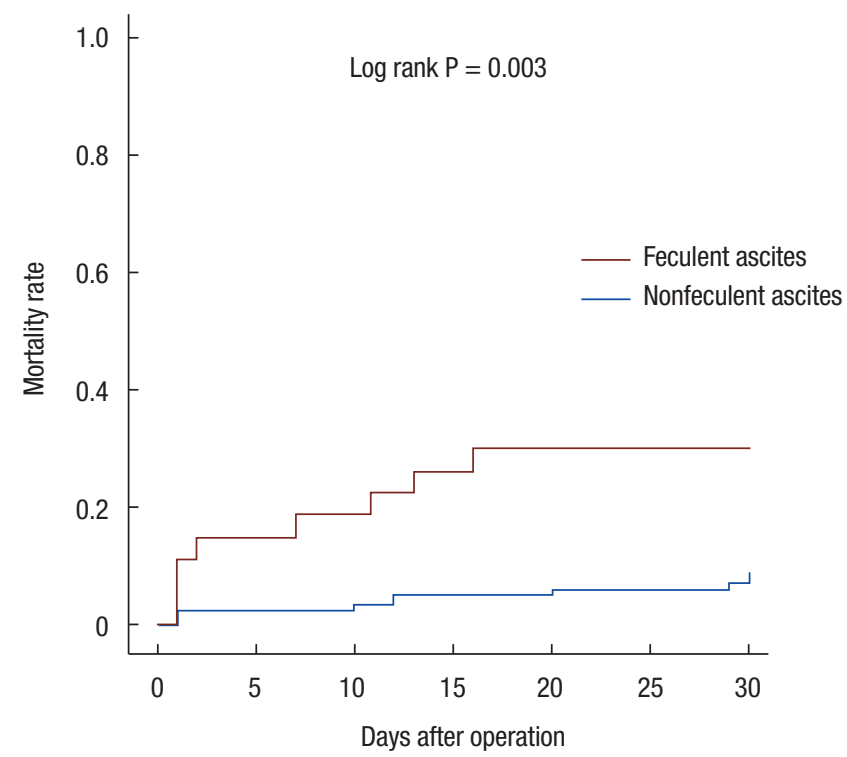

Fig. 2. Kaplan-Meier analysis of 30-day mortality in patients with feculent ascites and nonfeculent ascites after surgery for an intestinal perforation. A log-rank test indicated significantly greater mortality in patients with feculent ascites.

organ failure (100\%), cardiovascular events (50\%), and septic shock (42\%). Table 4 shows the results of the univariate analysis of factors associated with postoperative complications. The results show that advanced age $(\mathrm{P}=0.012)$, female sex $(\mathrm{P}=0.017)$, hypertension $(P=0.004)$, feculent ascites $(P=0.016)$, low white blood cell count $(P=0.012)$, low serum albumin $(P=0.001)$, and low estimated glomerular filtration rate (eGFR) $(\mathrm{P}<0.001)$ were significantly associated with complications. The multivariate analysis (Table 5) indicated that low eGFR $(\mathrm{P}=0.021)$, female sex $(\mathrm{P}=0.045)$, and elevated $\mathrm{C}$-reactive protein level $(\mathrm{CRP})(\mathrm{P}=$ 0.017 ) were significantly and independently associated with complications. Feculent ascites was a marginally significant factor $(\mathrm{P}=$ 0.051).

\section{DISCUSSION}

The purpose of this study was to identify the major predictors of morbidity and mortality after surgery for an intestinal perforation. Previous researchers reported that general colorectal surgery
Table 4. Univariate analysis of patient-related and surgery-related factors associated with postoperative complications within 1 month after surgery for an intestinal perforation ${ }^{\mathrm{a}}$

\begin{tabular}{|c|c|c|}
\hline Factor & Complications & P-value \\
\hline Age (yr) & & $0.012^{*}$ \\
\hline$<80$ & $52 / 98(53)$ & \\
\hline$\geq 80$ & $16 / 19(84)$ & \\
\hline Sex & & $0.017^{*}$ \\
\hline Male & $39 / 78(50)$ & \\
\hline Female & 29/39 (74) & \\
\hline Body mass index (kg/m) & & 0.057 \\
\hline$<18$ & 13/16 (81) & \\
\hline$\geq 18$ & $50 / 95(53)$ & \\
\hline Diabetes mellitus & & 0.267 \\
\hline Yes & $11 / 15(73)$ & \\
\hline No & $57 / 102(56)$ & \\
\hline Hypertension & & $0.004^{*}$ \\
\hline Yes & 27/34 (79) & \\
\hline No & $41 / 83(49)$ & \\
\hline Systolic blood pressure (mmHg) & & 1.000 \\
\hline$<100$ & $17 / 9$ (59) & \\
\hline$\geq 100$ & $53 / 88(60)$ & \\
\hline Heart rate (bpm) & & 0.344 \\
\hline$<100$ & $36 / 67(54)$ & \\
\hline$\geq 100$ & $32 / 50(64)$ & \\
\hline \multicolumn{3}{|l|}{ Time from symptom onset to surgery (hr) } \\
\hline$<24$ & $39 / 77(51)$ & \\
\hline$\geq 24$ & 27/38 (71) & \\
\hline Time from admission to surgery (hr) & & 0.648 \\
\hline$<24$ & 52/92 (57) & \\
\hline$\geq 24$ & $16 / 25(64)$ & \\
\hline Ascites & & $0.016^{\star}$ \\
\hline Feculent & 22/28 (79) & \\
\hline Nonfeculent & 45/86 (52) & \\
\hline White blood cells $\left(/ \mathrm{mm}^{3}\right)$ & & $0.012^{*}$ \\
\hline$<4,000$ & 16/19 (84) & \\
\hline$\geq 4,000$ & 52/98 (53) & \\
\hline Serum albumin (g/dL) & & $0.001^{*}$ \\
\hline$<3.5$ & 44/60 (73) & \\
\hline$\geq 3.5$ & 22/52 (42) & \\
\hline eGFR (mL/min/1.73 m²) & & $<0.001^{*}$ \\
\hline$<60$ & 33/38 (87) & \\
\hline$\geq 60$ & $33 / 74(45)$ & \\
\hline
\end{tabular}

Values are presented as number (\%).

eGFR, estimated glomerular filtration rate.

${ }^{a}$ Complications are in Fig. 3. ${ }^{*}<<0.05$, statistically significant. 


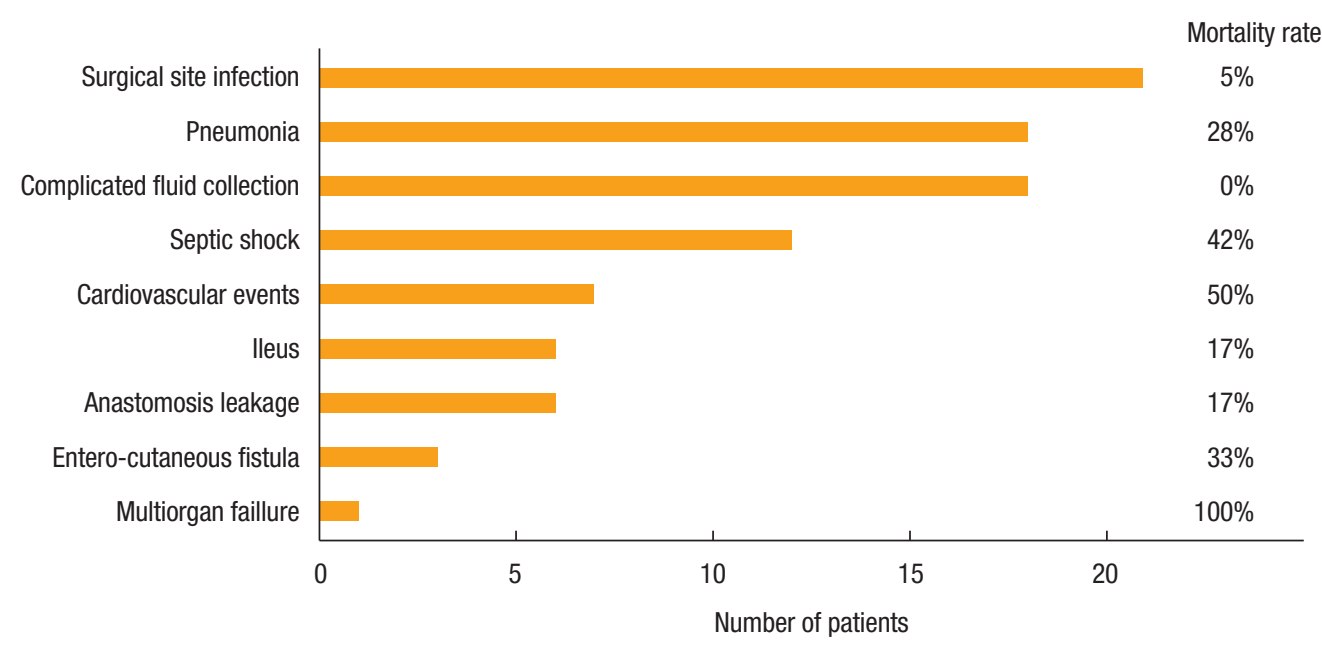

Fig. 3. Incidences and mortality rates of postoperative complications after surgery for an intestinal perforation.

Table 5. Multivariable analysis of factors associated with postoperative complications within one month after an intestinal perforation

\begin{tabular}{lccc}
\hline Factors & Adjusted OR & $95 \% \mathrm{Cl}$ & P-value \\
\hline Feculent ascites & 4.335 & $0.991-18.954$ & 0.051 \\
eGRF $<60 \mathrm{~mL} / \mathrm{min} / 1.73 \mathrm{~m}^{2}$ & 4.114 & $1.243-13.616$ & $0.021^{*}$ \\
Female sex & 3.244 & $1.026-10.255$ & $0.045^{\star}$ \\
CRP & 1.064 & $1.011-1.120$ & $0.017^{\star}$ \\
\hline
\end{tabular}

$\mathrm{OR}$, odds ratio; $\mathrm{Cl}$, confidence interval; eGFR, estimated glomerular filtration rate; CRP, C-reactive protein.

${ }^{*} P<0.05$, statistically significant.

had an overall mortality rate of 3\%-7\% and a morbidity rate of $20 \%-30 \%[13,14]$. In the case of surgery for an intestinal perforation, however, the reported mortality rate is $10 \%-15 \%$ and the morbidity rate is $30 \%-50 \%[1,15]$. In our study, the mortality rate was $13 \%$, and the morbidity rate was $60 \%$, in agreement with previous reports. The main results of this study are that low systolic blood pressure and feculent ascites are independent predictors of postoperative mortality, and that low eGRF, female sex, and high CRP are independent predictors of postoperative complications.

A previous study of patients with a stercoral perforation of the colon indicated that intra-abdominal infection was the second most common cause of septic shock after pulmonary infection [16]. Preoperative shock, usually septic shock, is a well-established risk factor for mortality following intestinal perforation. Septic shock caused by an intestinal perforation results from direct spillage of intestinal contents into the peritoneum (feculent ascites). This leads to entry of gram-negative and anaerobic bacteria, including Escherichia coli, Klebsiella pneumoniae, and Enterococcus faecalis, into the peritoneal cavity [17]. These bacteria produce endotoxins that activate inflammatory cascades, leading to the release of cytokines, such as tumor necrosis factor-alpha, interleukin (IL)-1, and IL-6, resulting in septic shock. Shinkawa et al. [10] previously reported that the in-hospital mortality from colonic perforation was 8 times higher in patients with septic shock than in those without septic shock. Several scoring systems that consider a patient's initial status to predict prognosis, such as the Acute Physiology and Chronic Health Evaluation II score [18] and the Simplified Acute Physiology Score, are available [19]. These scoring systems can be used to predict the prognosis of patients with intestinal perforations; however, they do not consider disease-specific conditions [12]. In this study, low initial systolic blood pressure and feculent ascites were significant and independent predictors of postoperative mortality. This means that preoperative sepsis is the most important factor associated with postoperative mortality.

Other research has established that malnutrition is independently associated with poor clinical outcomes among hospitalized patients, including longer hospital stay, increased costs, increased morbidity, and increased mortality, regardless of the underlying disease [20,21]. Nutritional status can be evaluated by using tools such as the Subjective Global Assessment [22, 23], the Mini Nutritional Assessment [24], and the Malnutrition Clinical Characteristics [25] tools. Previous research has validated these scoring systems, but these tools typically cannot be used in patients undergoing emergency operations. Serum albumin is a widely accepted indicator of nutritional status [26], although some controversy exists because albumin is a negative acute-phase reactant and hypoalbuminemia is a sign of systemic inflammation [27]. However, serum albumin is a better prognostic indicator than other scoring systems because it indicates protein-energy malnutrition resulting from the stress of illness, injury, or infection [28], all of which are associated with significantly increased risk of morbidity and mortality [29-31]. Serum albumin is also well known to be associated with surgical outcomes. For example, Gibbs et al. [32] reported that serum albumin concentration was a better predictor of surgical outcomes than many other preopera- 
tive factors in patients undergoing noncardiac surgery. Truong et al. [33] reported a linear relationship between hypoalbuminemia and morbidity and mortality following colorectal surgery. The present study also indicated that hypoalbuminemia was associated with poor surgical outcomes in patients with an intestinal perforation, although it was not a statistically independent risk factor for poor outcome.

We also identified factors related to complications following surgery for an intestinal perforation. Age, low BMI, chronic kidney disease, poor American Society of Anesthesiologists physical status, large blood loss, and long operation time are generally known to be risk factors for postoperative complications [34-36]. In the present study, feculent ascites and high CRP (indicators of severe intra-abdominal infection and inflammation) and impaired renal function were independently and significantly associated with complications. We were surprised to find that female sex increased the risk for complications. This may be due to the females in this study being older than the males $(68.4 \pm 15.4$ years vs. 64.8 \pm 16.0 years) or to postoperative pneumonia being more common in the females in this study than the males $(28.2 \%$ vs. $9.0 \%$, $\mathrm{P}=0.012$ ).

This study has some limitations that need to be emphasized. First, it was a retrospective study, so some variables that could be related with outcomes, such as $\mathrm{pH}$ from atrial blood gas analysis and the results of blood cultures, were not evaluated. Second, this was a single center study, so the results may not be applicable to other populations. Finally, because intestinal perforation is a rare condition, the study population was relatively small. This made estimating the prognostic values of some variables, such as age or time from admission to surgery, impossible.

In conclusion, the postoperative mortality of patients with an intestinal perforation was greater for those with low systolic blood pressure and feculent ascites. Females, as well as patients with low eGFR or high CRP, had increased risk of postoperative complications. Patients with any of these prognostic factors should be given more meticulous intraoperative and postoperative care to improve their outcomes.

\section{CONFLICT OF INTEREST}

No potential conflict of interest relevant to this article was reported.

\section{REFERENCES}

1. Bielecki K, Kamiński P, Klukowski M. Large bowel perforation: morbidity and mortality. Tech Coloproctol 2002;6:177-82.

2. Kriwanek S, Armbruster C, Beckerhinn P, Dittrich K. Prognostic factors for survival in colonic perforation. Int J Colorectal Dis 1994;9:158-62.

3. Pisanu A, Cois A, Uccheddu A. Surgical treatment of perforated diverticular disease: evaluation of factors predicting prognosis in the elderly. Int Surg 2004;89:35-8.

4. Ohmann C, Wittmann DH, Wacha H. Prospective evaluation of prognostic scoring systems in peritonitis. Peritonitis Study Group. Eur J Surg 1993;159:267-74.

5. Kriwanek S, Armbruster C, Dittrich K, Beckerhinn P. Perforated colorectal cancer. Dis Colon Rectum 1996;39:1409-14.

6. Serpell JW, Nicholls RJ. Stercoral perforation of the colon. Br J Surg 1990;77:1325-9.

7. Kyllönen LE. Obstruction and perforation complicating colorectal carcinoma. An epidemiologic and clinical study with special reference to incidence and survival. Acta Chir Scand 1987;153: 607-14.

8. Welch JP, Donaldson GA. Perforative carcinoma of colon and rectum. Ann Surg 1974;180:734-40.

9. Samalavicius NE, Kazanavicius D, Lunevicius R, Poskus T, Valantinas J, Stanaitis J, et al. Incidence, risk, management, and outcomes of iatrogenic full-thickness large bowel injury associated with 56,882 colonoscopies in 14 Lithuanian hospitals. Surg Endosc 2013;27:1628-35.

10. Shinkawa H, Yasuhara H, Naka S, Yanagie H, Nojiri T, Furuya Y, et al. Factors affecting the early mortality of patients with nontraumatic colorectal perforation. Surg Today 2003;33:13-7.

11. Biondo S, Ramos E, Deiros M, Ragué JM, De Oca J, Moreno P, et al. Prognostic factors for mortality in left colonic peritonitis: a new scoring system. J Am Coll Surg 2000;191:635-42.

12. Horiuchi A, Watanabe Y, Doi T, Sato K, Yukumi S, Yoshida M, et al. Evaluation of prognostic factors and scoring system in colonic perforation. World J Gastroenterol 2007;13:3228-31.

13. Alves A, Panis Y, Mathieu P, Mantion G, Kwiatkowski F, Slim K, et al. Postoperative mortality and morbidity in French patients undergoing colorectal surgery: results of a prospective multicenter study. Arch Surg 2005;140:278-83.

14. Ko CY, Chang JT, Chaudhry S, Kominski G. Are high-volume surgeons and hospitals the most important predictors of in-hospital outcome for colon cancer resection? Surgery 2002;132:26873.

15. Han EC, Ryoo SB, Park BK, Park JW, Lee SY, Oh HK, et al. Surgical outcomes and prognostic factors of emergency surgery for colonic perforation: would fecal contamination increase morbidity and mortality? Int J Colorectal Dis 2015;30:1495-504.

16. Engel C, Brunkhorst FM, Bone HG, Brunkhorst R, Gerlach H, Grond S, et al. Epidemiology of sepsis in Germany: results from a national prospective multicenter study. Intensive Care Med 2007; 33:606-18.

17. Pavlidis TE. Cellular changes in association with defense mechanisms in intra-abdominal sepsis. Minerva Chir 2003;58:777-81.

18. Knaus WA, Draper EA, Wagner DP, Zimmerman JE. APACHE II: a severity of disease classification system. Crit Care Med 1985;13: 818-29.

19. Le Gall JR, Lemeshow S, Saulnier F. A new Simplified Acute Physiology Score (SAPS II) based on a European/North American multicenter study. JAMA 1993;270:2957-63. 
20. Lew CC, Yandell R, Fraser RJ, Chua AP, Chong MF, Miller M. Association between malnutrition and clinical outcomes in the intensive care unit: a systematic review. JPEN J Parenter Enteral Nutr 2016 Feb 2 [Epub]. http://doi.org/10.1177/0148607115625638.

21. Hu WH, Cajas-Monson LC, Eisenstein S, Parry L, Cosman B, Ramamoorthy S. Preoperative malnutrition assessments as predictors of postoperative mortality and morbidity in colorectal cancer: an analysis of ACS-NSQIP. Nutr J 2015;14:91.

22. Detsky AS, McLaughlin JR, Baker JP, Johnston N, Whittaker S, Mendelson RA, et al. What is subjective global assessment of nutritional status? JPEN J Parenter Enteral Nutr 1987;11:8-13.

23. Coltman A, Peterson S, Roehl K, Roosevelt H, Sowa D. Use of 3 tools to assess nutrition risk in the intensive care unit. JPEN J Parenter Enteral Nutr 2015;39:28-33.

24. Guigoz Y, Vellas B, Garry PJ. Assessing the nutritional status of the elderly: The Mini Nutritional Assessment as part of the geriatric evaluation. Nutr Rev 1996;54(1 Pt 2):S59-65.

25. White JV, Guenter P, Jensen G, Malone A, Schofield M; Academy of Nutrition and Dietetics Malnutrition Work Group, et al. Consensus statement of the Academy of Nutrition and Dietetics/ American Society for Parenteral and Enteral Nutrition: characteristics recommended for the identification and documentation of adult malnutrition (undernutrition). J Acad Nutr Diet 2012;112: 730-8.

26. Buzby GP, Mullen JL, Matthews DC, Hobbs CL, Rosato EF. Prognostic nutritional index in gastrointestinal surgery. Am J Surg 1980;139:160-7.

27. Gabay C, Kushner I. Acute-phase proteins and other systemic responses to inflammation. N Engl J Med 1999;340:448-54.

28. Lipschitz DA. Protein calorie malnutrition in the hospitalized el- derly. Prim Care 1982;9:531-43.

29. Moghadamyeghaneh Z, Hwang G, Hanna MH, Phelan MJ, Carmichael JC, Mills SD, et al. Even modest hypoalbuminemia affects outcomes of colorectal surgery patients. Am J Surg 2015;210: 276-84.

30. Kong CH, Guest GD, Stupart DA, Faragher IG, Chan ST, Watters DA. Colorectal preOperative Surgical Score (CrOSS) for mortality in major colorectal surgery. ANZ J Surg 2015;85:403-7.

31. Detsky AS, Baker JP, O’Rourke K, Johnston N, Whitwell J, Mendelson RA, et al. Predicting nutrition-associated complications for patients undergoing gastrointestinal surgery. JPEN J Parenter Enteral Nutr 1987;11:440-6.

32. Gibbs J, Cull W, Henderson W, Daley J, Hur K, Khuri SF. Preoperative serum albumin level as a predictor of operative mortality and morbidity: results from the National VA Surgical Risk Study. Arch Surg 1999;134:36-42.

33. Truong A, Hanna MH, Moghadamyeghaneh Z, Stamos MJ. Implications of preoperative hypoalbuminemia in colorectal surgery. World J Gastrointest Surg 2016;8:353-62.

34. Manilich E, Vogel JD, Kiran RP, Church JM, Seyidova-Khoshknabi D, Remzi FH. Key factors associated with postoperative complications in patients undergoing colorectal surgery. Dis Colon Rectum 2013;56:64-71.

35. Cohen ME, Bilimoria KY, Ko CY, Hall BL. Development of an American College of Surgeons National Surgery Quality Improvement Program: morbidity and mortality risk calculator for colorectal surgery. J Am Coll Surg 2009;208:1009-16.

36. Slim K, Panis Y, Alves A, Kwiatkowski F, Mathieu P, Mantion G, et al. Predicting postoperative mortality in patients undergoing colorectal surgery. World J Surg 2006;30:100-6. 